\title{
Mucin histochemistry of stomach in metaplasia and adenocarcinoma: An observation
}

\author{
Prakas Kumar Mandal, \\ Sudipta Chakrabarti ${ }^{1}$, Amit Ray ${ }^{2}$, \\ Bitan Chattopadhyay, \\ Shikha Das ${ }^{4}$ \\ Departments of Hematology, and \\ ${ }^{2}$ Pediatric Surgery, NRS Medical \\ College, ${ }^{1}$ Department of Pathology, \\ ESI PGIMSR, Manicktala, \\ ${ }^{3}$ Department of General Surgery, \\ Institute of Postgraduate Medical \\ Education and Research, \\ ${ }^{4}$ Department of Pathology, R. G. \\ Kar Medical College and Hospital, \\ Kolkata, West Bengal, India
}

\begin{abstract}
A B S T R A C T
Background: There is a variable pattern of occurrence of gastric carcinomas world-wide, partially reflecting the frequency of various changes of gastric mucosa from, which such neoplasm occur. Many cases of gastric carcinoma originate in the background of chronic gastritis caused by Helicobacter pylori. Subsequent intestinal metaplasia (IM) can be morphologically classified by routine and special histopathological stains. Materials and Methods: The present study was conducted over the 2 years at NRSMC \& $\mathrm{H}$, Kolkata. Aims of the present study were to search for evidences of $H$. pylori infection, classification of different metaplastic and/or malignant changes, identification of types of mucin by mucin histochemistry and their interrelationship in gastrectomy and gastric biopsy specimens (total 70). After obtaining clinical history, radiological and endoscopic findings were noted. After macroscopic study of the specimen, hematoxylene and eosin, southgate mucicarmine, periodic acid schiff-alcian blue (PAS-AB) and gomori aldehyde fuchsin (GAF)/AB staining were performed to classify gastric carcinoma and metaplastic changes and to correlate with staining patterns of mucin. Results: The overall male to female ratio was 2.89:1. Age ranged from 22 years to 78 years and the commonest age group of gastric carcinomas being 41-50 years (26 cases, $37.1 \%$ ). Gastric adenocarcinoma was found in $61(87.1 \%)$ cases $(22.9 \%$ were of intestinal type and $77.1 \%$ of diffuse type) and only IM was found in $9(12.9 \%)$ cases. Overall the rapid urease test was positive in $18(25.7 \%)$ cases majority of which showing either pure IM or IM associated with intestinal type of gastric carcinoma. All diffuse types of gastric carcinoma (47 cases, $77.1 \%$ ) were showed PAS positive staining (indicating neutral mucin) whereas in $15(65.2 \%)$ cases of IM columnar cells stained with AB (representing acidic mucin). GAF/AB stain revealed Type II IM in 10 (43.5\%) cases and Type III IM in $4(17.4 \%)$ cases. Conclusion: Routine and special histological staining is particularly useful for histological subtyping of gastric carcinomas and IMs.
\end{abstract}

Key words: Gastric carcinoma, histochemistry, intestinal metaplasia of stomach, mucin stain

\section{INTRODUCTION}

The incidence of gastric carcinoma has declined by twothirds over the last few decades in some countries such as United States and England while in some others, such as in Japan, Chile and Italy, it remains inordinately high. ${ }^{[1]}$ In most instances, gastric carcinoma arises in a background of chronic atrophic gastritis with intestinal metaplasia (IM) and is preceded by various stages of dysplasia and carcinoma in situ. ${ }^{[2]} \mathrm{IM}$ is referred to as progressive replacement of

\begin{tabular}{|l|l|}
\hline \multicolumn{2}{|c|}{ Access this article online } \\
\hline Quick Response Code: & Website: \\
\hline & www.jmpo.org \\
\hline
\end{tabular}

gastric mucosa by epithelium having the features of the intestinal epithelium of either small or large bowel type. IM has been divided into Type-I (complete) and Types-II and III (incomplete). ${ }^{[3]}$ Infection with Helicobacter pylori results in chronic active gastritis, which consistently affects the gastric antrum. ${ }^{[4]}$ Finally persistent $H$. pylori may lead to the progression of chronic active gastritis to chronic gastritis with a variable degree of atrophy. Chronic atrophic gastritis and its associated lesion, IM are the most ubiquitous precursors of intestinal type gastric carcinoma. ${ }^{[5]}$ Demonstration of mucin in gastric metaplastic changes and in invasive carcinomas is imperative as the Lauren classification has been incorporated in the World Health Organization classification of tumors. The Lauren classification has proven useful in evaluating the natural history of gastric carcinoma, particularly with regard to its association with environmental factors, incidence trends and its precursors and is based on metaplastic epithelium, growth pattern and the character of mucin. ${ }^{[6]}$ 
The present prospective study was undertaken to classify different types of IM and gastric adenocarcinoma, to find evidences of infection of $H$. pylori and to correlate the patterns of different types of mucin in such cases. The study also intended to assess whether different mucin stains can assist in the histological subtyping of IM and gastric carcinoma.

\section{MATERIALS AND METHODS}

The present study was conducted during a 2 years period at NRSMC \& H, Kolkata. Gastrectomy and gastric biopsy specimens of patients having clinical, radiological and endoscopic features suggestive of gastric malignancy were selected for the present study.

\section{History, clinical finding, laboratory and radiological investigations}

Detailed history, clinical features especially duration of symptoms, features suggestive of $H$. pylori infection was evaluated. In all patients, findings of routine blood and stool examination (including occult blood test) were noted. Radiological examinations \{ultrasonography (USG), computed tomography (CT) scan, Barium meal radiography $\}$ and endoscopy were done to assess the site and nature of the lesion. Endoscopic biopsy specimens were examined for $H$. pylori by rapid urease test (RUT). In cases of gastrectomy specimen, two gastric mucosal biopsies from the prepyloric antrum and lower body of the gastrectomy specimen were obtained before fixation and were immediately processed with the RUT kit and color change was monitored for up to 24 h. ${ }^{[7]}$

\section{Pathological evaluation}

In gross examination, type of specimen was noted. In gastrectomy specimens, site, size and character of the lesion, lymph node and marginal status were noted. Blocks were prepared from tissues taken as per standard protocol. For microscopic study, hematoxylene and eosin $(\mathrm{H}$ and E), southgate mucicarmine and periodic acid schiffalcian blue (PAS-AB) were performed for morphological evaluation and the typing of mucin [Figure 1]. Gomori aldehyde fuchsin (GAF) - AB staining was done in cases of IM. For isolation of $H$. pylori, giemsa staining was performed.

\section{RESULTS}

A total of 70 cases - 26 endoscopic biopsies and 44 gastrectomy specimens were included in the study. The overall male to female ratio was 2.89:1 (52 being males and 18 females). Age ranged from 22 years to 78 years, the mean age being 46.43 years. A total of 26 patients
(37.1\%) of were found in 41-50 years age group followed by $19(27.1 \%)$ in the $51-60$ years and $9(12.9 \%)$ in $61-70$ years group [Table 1].

Routine blood examination revealed anemia in 57 (81.4\%) patients, 54 of whom had gastric carcinoma. Occult blood in stool was present in $28(40.0 \%)$ cases of gastric carcinoma.

Mucosal biopsies were tested for the presence of $H$. pylori by RUT in all 70 cases. Overall the test was positive in 18 $(25.7 \%)$ cases comprising $7(38.9 \%)$ showing pure IM, 8 (44.4\%) showing IM associated with intestinal type of gastric carcinoma and $3(16.7 \%)$ showing diffuse type of gastric carcinoma.

Site of the lesions by endoscopy and gross examination showed $52(74.3 \%)$ cases to be in the pyloric region, $17(24.3 \%)$ in the body and $1(1.4 \%)$ at cardiac end. The size of ulcers and tumors ranged from $1.5 \mathrm{~cm}$ to $8 \mathrm{~cm}$ in the

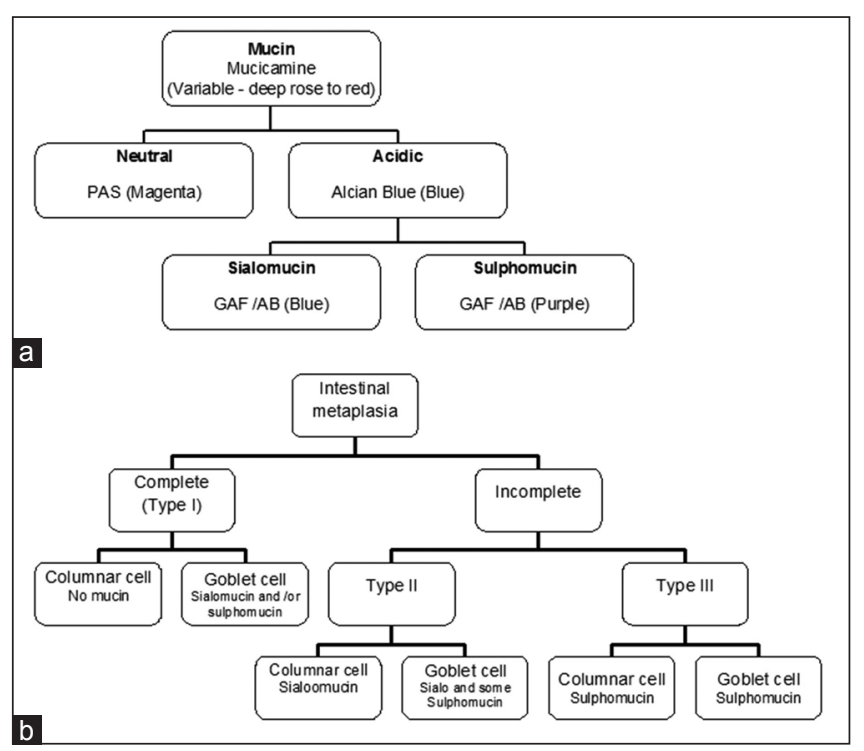

Figure 1: (a) Algorithm of different types mucin, stains for demonstration and color for positivity (in bracket) used in the present study. Gomori aldehyde fuchsin - alcian blue. (b) Types of mucin present in intestinal metaplasia

\begin{tabular}{|c|c|c|c|c|c|}
\hline \multirow[t]{2}{*}{ Age group (years) } & \multicolumn{2}{|c|}{$\begin{array}{c}\text { Male } \\
(n=52,74 \cdot 3 \%)\end{array}$} & \multicolumn{2}{|c|}{$\begin{array}{c}\text { Female } \\
(n=18,25.7 \%)\end{array}$} & \multirow[t]{2}{*}{ Total (\%) } \\
\hline & Pure IM & $\begin{array}{c}\text { Gastric } \\
\text { carcinoma }\end{array}$ & Pure IM & $\begin{array}{c}\text { Gastric } \\
\text { carcinoma }\end{array}$ & \\
\hline Less than 30 & 1 & 3 & 1 & 3 & $8(11.4)$ \\
\hline $31-40$ & 0 & 5 & 0 & 1 & $6(8.6)$ \\
\hline $41-50$ & 3 & 19 & o & 4 & $26(37.1)$ \\
\hline $51-60$ & 2 & 10 & 1 & 6 & $19(27.1)$ \\
\hline $61-70$ & 1 & 7 & 0 & 1 & $9(12.9)$ \\
\hline 71-80 & o & 1 & o & 1 & $2(2.9)$ \\
\hline Total & 7 & 45 & 2 & 16 & 70 \\
\hline
\end{tabular}

IM - Intestinal metaplasia 
greatest dimension with a predominance of a size between $2 \mathrm{~cm}$ and $3 \mathrm{~cm}$ in 26 cases (37.1\%). Greatest dimension of lesions in cases of pure IM varied from $1.5 \mathrm{~cm}$ to $4 \mathrm{~cm}$. In 51 cases of gastric carcinomas (83.6\%) USG revealed the site, size and extent of the space occupying lesion and/or lymph node enlargement, the remaining 10 cases (16.4\%) were inconclusive. These 10 cases were further investigated with CT scan, which revealed the details of the lesions with additional information such as involvement of adjacent gut, omentum and lymph nodes, etc.

\section{Histopathological study}

Gastric adenocarcinoma was diagnosed in 61 (87.1\%) cases (45 males and 16 females). The male to female ratio was 2.81:1. Among cases of gastric adenocarcinoma, 14 (22.9\%) cases were of intestinal type and $47(77.1 \%)$ cases of diffuse type. Both categories showed a male predominance.

IM was detected in routine $\mathrm{H}$ and $\mathrm{E}$ stain in 23 cases. Among these, IM was associated with gastric carcinoma in 14 cases $(22.9 \%)$ and rest (9 cases, $12.9 \%)$ was not associated with malignancy (pure IM).

By Southgate Mucicarmine, 5 cases $(7.1 \%)$ were strongly positive for mucicarmine, 12 cases $(17.1 \%)$ showed weak positivity and 53 cases $(75.7 \%)$ showed no staining.

In PAS-AB technique, all diffuse types of gastric carcinoma (47 cases, $77.1 \%$ ) were reactive with PAS staining due to the presence of neutral mucin. In contrast intestinal type of adenocarcinomas was reactive [Figure 2] with AB. Among 23 cases of IM, in 15 cases $(65.2 \%)$, columnar cells stained blue [Figure 3] with AB (representing acidic mucin) and these were categorized as belonging to subtype of Type II and/or Type III IM. In 8 case (34.8\%) columnar cells were

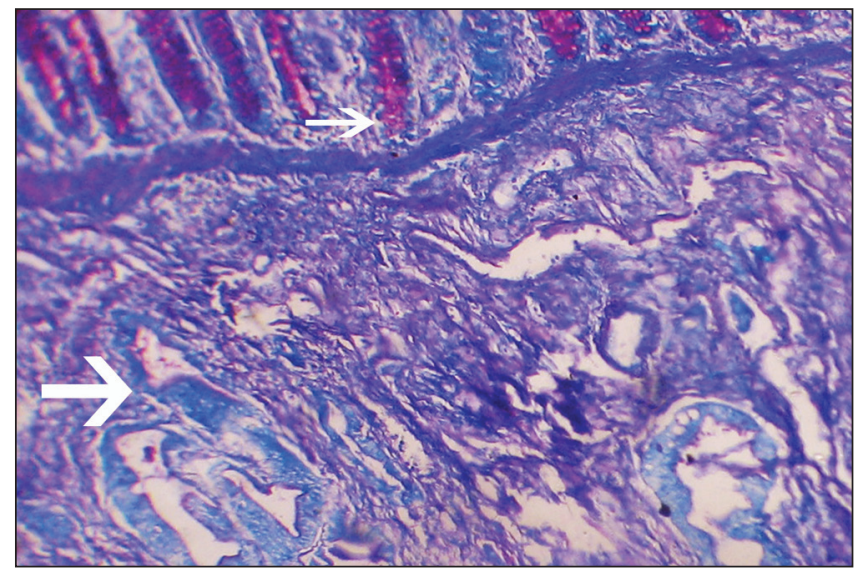

Figure 2: Periodic acid schiff-alcian blue (PAS-AB) stain showing $A B$ positive (blue) glands (larger arrow) of intestinal type of gastric adenocarcinoma invading through muscle layers with some PAS positive (magenta) normal glands at the top (smaller arrow) (PAS-AB, $\times 100$ ) not reactive with any stain and these were categorized as Type I IM (no mucin) [Table 2].

GAF/AB stain was carried out in all 23 IM cases. 8 cases $(34.8 \%)$ showed no mucin in the columnar cells (indicating Type I IM), 10 cases (43.5\%) showed blue or clear with a trace of purple (indicating Type II IM) and all purple in 4 cases (17.4\%, Type III IM). In the Types I and II of IM the goblet cells showed positivity for sialomucin, but were absent in Type III of IM cases (i.e., no sialomucins). Neither the goblet cells nor the columnar cells were positive in one case - where the type of IM remained undetermined [Table 3].

Giemsa stain revealed H. pylori in 15 (21.4\%) cases. Among total 23 cases with IM noted, $H$. pylori was identified in $13(56.5 \%)$ cases.

\section{DISCUSSION}

Among the total 70 cases, 61 cases were diagnosed as gastric adenocarcinoma. In cases of gastric carcinomas, 45 patients were male and 16 were female. The male to female ratio were 2.81:1, which is similar to ReMine and Priestley ${ }^{[8]}$ and Hawley et al.. ${ }^{[9]}$ wherein, the ratio were 2.5:1, 2.2:1

\begin{tabular}{|c|c|c|c|c|c|}
\hline $\begin{array}{l}\text { Reaction } \\
\text { pattern }\end{array}$ & $\begin{array}{l}\text { Mucin } \\
\text { content }\end{array}$ & Pure IM & $\begin{array}{l}\text { IM associated } \\
\text { with intestinal } \\
\text { type of gastric } \\
\text { carcinoma }\end{array}$ & $\begin{array}{l}\text { Diffuse type } \\
\text { of gastric } \\
\text { carcinoma }\end{array}$ & Total (\%) \\
\hline PAS positive & $\begin{array}{l}\text { Neutral } \\
\text { mucin }\end{array}$ & o & 0 & 47 & $47(67.1)$ \\
\hline $\begin{array}{l}\text { Alcian blue } \\
\text { positive }\end{array}$ & $\begin{array}{l}\text { Acidic } \\
\text { mucin }\end{array}$ & 5 & 10 & o & $15(21.4)$ \\
\hline None & None & 4 & 4 & 0 & 8 (11.4) \\
\hline
\end{tabular}

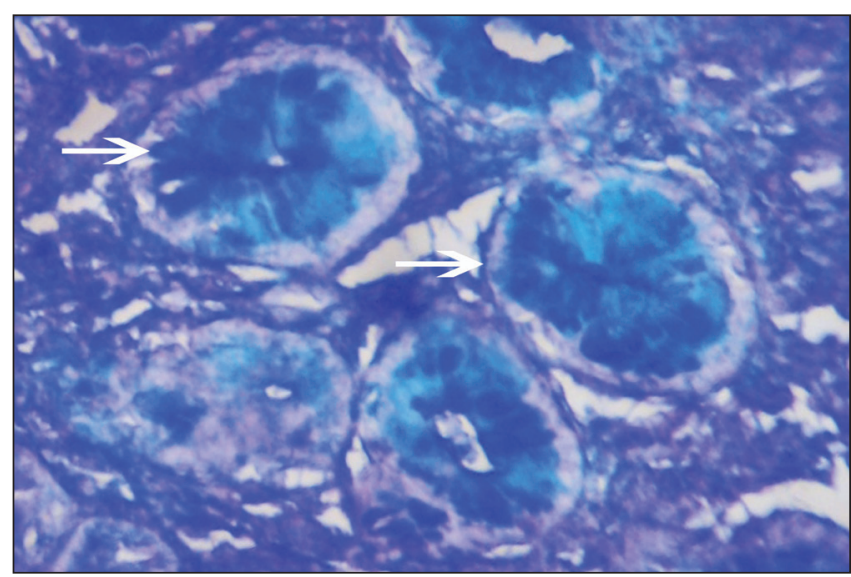

Figure 3: Intestinal type of metaplasia showing positive stain by alcian blue $(A B)(A B, \times 100)$ 


\begin{tabular}{llll}
\hline \multicolumn{3}{l}{ Table 3: Subtyping of $\mathbf{2 3}$ cases of IM using } \\
gomori aldehyde fuchsin-alcian blue stain
\end{tabular}

IM - Intestinal metaplasia

respectively. Analyzing the number of patients in different age groups, it was observed that there is a steady increase of occurrence with increasing age group reaching a maximum at the range of 41-50 years. Thereafter, the occurrence has declined in the higher age group. The observation of age in this cohort of patients of the present study is similar as that observed by other Indian authors. ${ }^{[10,11]}$

Type I IM (complete) closely resembles normal small intestinal mucosa with goblet cells and absorptive cells with a brush border and presence of Paneth cells. ${ }^{[12]}$ In incomplete IM typical intestinal enterocytes are replaced by a population of partially differentiated columnar mucus cells (intermediate cells) lacking a well-developed brush border. ${ }^{[13]}$ Type II IM shows some glandular distortion and consists of goblet cells and columnar mucus cells secreting sialomucins. The goblet cells may also occasionally secrete sulphomucins. There are few absorptive cells. Type III is the least common and is distinguished by the presence of glandular distortion and columnar mucus cells containing sulphomucins. The goblet cells secrete either sialo- or sulphomucins, which is significant as cases containing sulphomucins in both goblet cells and columnar cells may have a higher risk of developing gastric cancer. ${ }^{[14]}$

In the present study, RUT positivity was more with pure IM cases (7 out of $9,77.8 \%$ ) in comparison with IM associated with intestinal type (8 out of $14,57.1 \%$ ) and diffuse type ( 3 out of 47 cases, $6.4 \%$ ) of gastric carcinoma. The positivity was more in Type I and Type II cases compared with Type III (in both groups of pure IM and IM associated with intestinal type of gastric carcinoma), which is same as that observed by Craanen $e t a l .{ }^{[15]}$ These authors also observed that Type III IM was found less often in the $H$. pylori positive patients and suggested that the gastric milieu in Type III IM cases is less appropriate for H. pylori. Type III IM might be regarded as a marker of possibly increased risk of gastric cancer and the lower prevalence H. pylori in Type III IM cases might be the result of severe changes in mucosal architecture. However, Satarkar et al., ${ }^{[16]}$ from Mumbai, India found no relation between $H$. pylori infection and development of IM in their series.

Mucicarmine stain is believed to stain many types mucin. Acidic mucins are specifically stained with this procedure, but neutral mucin and certain acidic sulphated mucin fail to show appreciable staining with it. ${ }^{[17]}$ Thus failure of tissue to stain does not rule out the presence of other mucins. The normal gastric gland cells and cells in diffuse type of gastric adenocarcinoma have neutral mucin, but the metaplastic gland cells have either acidic mucin (as noted in Type II IM) or sulphomucin (as observed in Type III IM). Type I IM have no mucin in the glandular columnar cells and are not stained with Southgate mucicarmine technique. Thus with Southgate's mucicarmine technique, a variable staining pattern was noted, which was not helpful in subtyping cases of IM and was also unsuitable in detecting the level of infiltration/invasion in cases of diffuse type of gastric carcinoma.

With PAS-AB stain the columnar cells demonstrated neutral mucin (magenta color - PAS positive) in diffuse type of gastric carcinoma in $47(67.1 \%)$ cases. Acidic mucins (blue color - $\mathrm{AB}$ positive) were demonstrated in Types II and III IM in $15(65.2 \%)$ cases. In 8 (34.8\%) cases there was no demonstrable mucin, i.e., Type I IM showed negative for both PAS and $\mathrm{AB}$. Thus, the technique was very much helpful in identifying IM as well as the diffuse type of gastric carcinoma. Several workers, notably Filipe et al. ${ }^{[14]}$ have documented a strong association between Type III IM and development of cancer and proposed a role of routine subtyping of IM in cancer surveillance.

For the subtyping of IM only the nature of columnar cell mucin, i.e., sialo or sulphomucins was considered and that of goblet cell mucin was ignored using GAF/AB stain. Type II IM, 10 cases (43.5\%) showed positive stain for sialomucin (blue color in columnar cells) whereas Type III IM 4 cases $(17.4 \%)$ showed a positive stain for sulphomucin (purple color in columnar cells). No color in columnar cells was interpreted (as no mucin present) in 8 cases $(34.8 \%$ ).

Therefore in the present study, the occurrence of IM of any pattern was $32.86 \%(23 / 70)$ which is comparable with figures of $28-33 \%$ reported by other studies. ${ }^{[14,18,19]}$ The occurrence of IM subtypes in the present study is nearly the same as that observed by Filipe et al., ${ }^{[18]}$ in a prospective study in three centers and by Shah et al. ${ }^{[2]}$ The single case (Case number 19) where subtyping could not be done in spite of repetition of the procedure indicates a failure of technique in identifying all suphomucins. The possibility 
as proposed by Spicer and Meyer ${ }^{[21]}$ is that there is a low level of sulphation or masking of weakly purple sulphated acid mucin by a stronger blue signal from the adjacent sialomucin.

\section{CONCLUSION}

Among the present cohort of 70 cases, several points can be highlighted from the observed data. The occurrence of gastric carcinoma is almost 3 times in male compared to female and in the age group of 41-50 years. RUT positivity was higher in pure IM cases $(77.8 \%)$ compared with IM associated with intestinal type $(57.1 \%)$ and diffuse type $(6.4 \%)$ of gastric carcinoma. Applying PAS-AB stain, the columnar cells demonstrated neutral mucin in $67.1 \%$ cases of diffuse type of gastric carcinoma and acidic mucins in $65.2 \%$ cases of IM (both Types II and III) - hence a suitable technique for identification of IM and diffuse type of gastric carcinoma. However, in difficult cases to demonstrate invading cells, immunohistochemistry will need to be used especially when a radical surgery is to be performed. For subtyping of IM only, the nature of columnar cell mucin was considered, using GAF/AB stain, which revealed Type II IM in 43.5\% cases and Type III IM in $17.4 \%$ cases. Thus using routine and special histological staining, histological subtyping of gastric carcinomas and IMs can be performed. These techniques are particularly suitable for countries like India as they can substantially contribute in the definite classification of gastric IM and carcinoma.

\section{REFERENCES}

1. Noguchi $Y$, Yoshikawa T, Tsuburaya A, Motohashi H, Karpeh MS, Brennan MF. Is gastric carcinoma different between Japan and the United States? Cancer 2000;89:2237-46.

2. Bronner MP. Gastric cancer and intestinal metaplasia. Hum Pathol 1999;30:733.

3. Rothery GA, Day DW. Intestinal metaplasia in endoscopic biopsy specimens of gastric mucosa. J Clin Pathol 1985;38:613-21.

4. Rauws EA, Langenberg W, Houthoff HJ, Zanen HC, Tytgat GN. Campylobacter pyloridis-associated chronic active antral gastritis. A prospective study of its prevalence and the effects of antibacterial and antiulcer treatment. Gastroenterology 1988;94:33-40.

5. Correa P. Precursors of gastric and esophageal cancer. Cancer 1982;50:2554-65.

6. Fenoglio-Preiser C, Muñoz N, Carneiro F, Powell SM, Correa P, Rugge M, et al. Gastric carcinoma. In: Hamilton SR, Aaltonen LA, editors. World Health Organization Classification of Tumours, Pathology and Genetics of Tumours of the Digestive System. Lyon: IARC Press; 2000. p. 37-67.

7. Kim SI, Jin SH, Lee JH, Min JS, Bang HY, Lee JI. An alternative method for a rapid urease test using back-table gastric mucosal biopsies from gastrectomy specimen for making the diagnosis of Helicobacter pylori infection in patients with gastric cancer. J Korean Gastric Cancer Assoc 2009;9:172-6.

8. ReMine $\mathrm{WH}$, Priestley JT. Trends in prognosis and surgical treatment of cancer of the stomach. Ann Surg 1966;163:736-45.

9. Hawley PR, Westerholm P, Morson BC. Pathology and prognosis of carcinoma of the stomach. $\mathrm{Br} \mathrm{J}$ Surg 1970;57:877-83.

10. Bazaz-Malik G, Lal N. Malignant tumours of the digestive tract. A twenty five year study. Indian J Pathol Microbiol 1989;32:179-85.

11. Devi KR, Suvarna N. Pattern of gastrointestinal tumours in North Kerala. Indian J Cancer 1980;17:159-63.

12. Jass JR. Role of intestinal metaplasia in the histogenesis of gastric carcinoma. J Clin Pathol 1980;33:801-10.

13. Matsukura N, Suzuki K, Kawachi T, Aoyagi M, Sugimura $\mathrm{T}$, Kitaoka $\mathrm{H}$, et al. Distribution of marker enzymes and mucin in intestinal metaplasia in human stomach and relation to complete and incomplete types of intestinal metaplasia to minute gastric carcinomas. J Natl Cancer Inst 1980;65:231-40.

14. Filipe MI, Muñoz N, Matko I, Kato I, Pompe-Kirn V, Jutersek A, et al. Intestinal metaplasia types and the risk of gastric cancer: A cohort study in Slovenia. Int $\mathrm{J}$ Cancer 1994;57:324-9.

15. Craanen ME, Blok P, Dekker W, Ferwerda J, Tytgat GN. Subtypes of intestinal metaplasia and Helicobacter pylori. Gut 1992;33:597-600.

16. Satarkar RP, Sawant P, Nanivadekar S, Shroff C. Helicobacter pylori and intestinal metaplasia of gastric mucosa. Indian J Gastroenterol 1997;16:16-7.

17. Totty BA. Mucins. In: Bancroft JD, Gamble M, editors. Theory and Practice of Histological Techniques. $5^{\text {th }}$ ed. London: Churchill Livingstone; 2002. p. 163-200.

18. Filipe MI, Potet F, Bogomoletz WV, Dawson PA, Fabiani $\mathrm{B}$, Chauveinc $\mathrm{P}$, et al. Incomplete sulphomucin-secreting intestinal metaplasia for gastric cancer. Preliminary data from a prospective study from three centres. Gut 1985;26:1319-26.

19. Ramesar KC, Sanders DS, Hopwood D. Limited value of type III intestinal metaplasia in predicting risk of gastric carcinoma. J Clin Pathol 1987;40:1287-90.

20. Shah KA, Deacon AJ, Dunscombe P, Price AB. Intestinal metaplasia subtyping: Evaluation of Gomori's aldehyde fuchsin for routine diagnostic use. Histopathology 1997;31:277-83.

21. Spicer SS, Meyer DB. Histochemical differentiation of acid mucopolysaccharides by means of combined aldehyde fuchsin-alcian blue staining. Tech Bull Regist Med Technol 1960;30:53-60.

How to cite this article: Mandal PK, Chakrabarti S, Ray A, Chattopadhyay B, Das S. Mucin histochemistry of stomach in metaplasia and adenocarcinoma: An observation. Indian J Med Paediatr Oncol 2013;34:229-33.

Source of Support: Nil, Conflict of Interest: None declared. 